\title{
O Direito Liberal À LUZ do PENSAMENTO HABERMASIANO
}

\author{
[The Liberal LaW IN THE Light OF THE Habermasian thought]
}

Resumo: O Direito liberal procede da ideia kantiana de um acordo de arbítrios conforme uma lei de liberdade externa, assegurando a ideia de um radicalismo pós-religioso de legitimidade e sem fundamentos metafísicos (Nozick). Habermas aproveita os sentidos do Direito liberal de Nozick e Kant, liberdade e não fundacionismo e associa a crítica ao Direito socialista a uma visão construtiva que, assim como Rawls (e seu pluralismo razoável), busca pensar as pretensões de um Direito democrático no espaço público. Superando a dicotomia socialista-liberal do século XX, Habermas busca manter a democracia e a pósmetafísica como elementos de um Direito pluralista que através do procedimentalismo institucionalizador das conquistas do espaço público movido pela razão comunicativa, possa assegurar as pretensões de legitimação da liberdade com as necessárias visões da "Teoria Crítica" sobre a legitimação da democracia no capitalismo tardio, preservando as autonomias pública e privada da tradição republicana e liberal de Kant.

Palavras-ChaVe: Liberalismo; Democracia; Legitimação; Procedimentalismo
ABSTRACT: The liberal Law proceeds from the Kantian idea of an arbitration agreement according to a law of external freedom, assuring the idea of a post-religious radicalism of legitimacy and without metaphysical foundations (Nozick). Habermas uses the senses of Nozick and Kant's liberal Law, freedom and non-foundationalism, and associates criticism with socialist Law with a constructive view that, like Rawls (and his reasonable pluralism), seeks to think the claims of a democratic Law in the public space. Overcoming the socialist-liberal dichotomy of the twentieth century, Habermas seeks to maintain democracy and post-metaphysics as elements of a pluralist Law that through institutionalizing proceduralism of the achievements of public space moved by communicative reason, can ensure the claims of legitimizing freedom with the necessary views of the Critical Theory on the legitimation of democracy in late capitalism, preserving the public and private autonomy of the republican and liberal tradition of Kant.

KEYwORDS: Liberalism; Democracy; Legitimation; Procedimentalism

\section{INTRODUÇão: DiREITO, LIBERDADE E LIBERALISMO}

$\mathrm{P}$ artiremos de um ponto de discussão teórica que defina um conceito básico de liberalismo, conceito político que se vincula na origem à noção de Direito contratual, conforme a linguagem filosófico-política do contratualismo: a existência de um movimento dos corpos individuais ${ }^{1}$, expresso em um nível de linguagem e de paixões que 
movem o ser individual à realidade externa de seu próprio corpo e estabelece uma ação eficaz mediante influenciar causas naturais através de sua vontade como deliberação (sopesamento do entendimento sobre as paixões).

Usando seu entendimento (faculdade de calcular o uso dos nomes) para deliberar e distinguir pensamentos (que como reflexos de estímulos sensoriais são um fluxo confuso em nossa mente) a fim de agir, a linguagem torna-se um mediador de sentimentos e limitador das ações, criando um espaço de ação comum, sob o poder comum o ser humano estabelece a sociedade.

Estar em liberdade para Hobbes é sopesar as paixões que estão em nossa natureza, tumultuárias em seu conflito com as paixões dos demais, regidos todos os homens pela busca da felicidade, que nada mais é que ampliação sucessiva dos desejos ${ }^{2}$ e o desejo de poder presente em todos.

Buscar a própria felicidade, cumprir com seus interesses parece o movimento natural dos homens e sua ação em busca da satisfação individual. $\mathrm{O}$ caráter individual do exercício da liberdade é frisado por Hobbes ${ }^{3}$ como sua característica determinativa, o que especifica o interesse é o mesmo ser do indivíduo e sua exercitação do poder de fazer valer suas paixões sem que haja impedimentos externos.

As paixões estão em conflito e o desejo de poder recíproco gera a luta entre os seres humanos, o naturalismo de Hobbes em descrever a luta das paixões humanas necessita de uma forma jurídica que equilibre os conflitos, daí o pacto de submissão que os indivíduos fazem com o ente de exercício de poder que é o Estado.

Se Hobbes pode ser considerado um liberal, o é no sentido completamente negativo: a liberdade sob coerção no âmbito da soberania do Estado é uma necessidade absoluta de proteção do individuo.

Em Locke, a liberdade no hipotético "estado natural” assumirá a função positiva de ser uma liberdade produtiva e adequada aos fins do mercado, possibilitando o labor e o gozo da propriedade e da vida privada, bem como de valorização da vida individual: é a confiança liberal na livre iniciativa que se justifica no pensamento do filósofo inglês. O pacto político será uma garantia dessa liberdade, e se não a assegurar poderá ser desfeito, e mesmo assim deve ser regulado pela soberania do parlamento, jamais admitindo o arbítrio do poder executivo.

Discutir Política é debater sobre valores e suas formas conflituosas de concretização através das relações de poder. A tradição contratualista frisa esse debate de Kant a Rawls no aspecto de uma aliança do Direito com a Política. Embora Kant tenha autonomizado o Direito tomando-o como um conjunto de leis, o que o aproxima do próprio conceito de Estado, ele não reduziu o Direito ao Estado, pois a condição transcendental de toda a coerção estatal é sua relação com a legitimidade da manutenção da liberdade do cidadão, que antecede o Estado, e não a redução da liberdade do cidadão ao poder estatal. O regime republicano para Kant é o único capaz de assegurar a liberdade do arbítrio dentro da lei, onde cada qual possa propor fins sem entrar em contradição com um bem comum formal, previsto como projeção de uma norma universal de liberdade protegida pela lei jurídica ${ }^{4}$.

Como aponta Viriato Soromenho Marques, o programa liberal francês resume o projeto político liberal de uma maneira ampla:

- exigência da separação entre os três poderes do Estado;

- reconhecimento do princípio representativo para a constituição do órgão deliberativo;

- defesa do direito de voto censitário, com a separação (idêntica à introduzida por 
Sieyès na Constituição Francesa de 1791) entre cidadãos activos e passivos. Esta concepção, embora muito longe da actual doutrina do voto universal, constituía então um enorme passo em frente relativamente à prática britânica, defendida ardentemente por Burke e pelos seus discípulos germânicos, segundo a qual o direito eleitoral deveria estar em correspondência directa com a extensão e valor da propriedade, sobretudo de base fundiária;

- obrigação, por parte do Estado, do reconhecimento de direitos invioláveis dos cidadãos, como liberdade de expressão, de deslocação, assim como o direito à assistência pública em caso de necessidade etc;

- abolição dos privilégios de casta da nobreza e do clero;

- consagração do mérito como princípio para a admissão a cargos públicos.

Conforme Berlin ${ }^{5}$, na tradição do individualismo liberal, sua liberdade política é uma liberdade negativa, imiscui-se de uma ação forçada, o Estado deve respeitar o indivíduo e suas disposições. O Estado se nega a interferir na liberdade individual.

Berlin observa a liberdade negativa como o cerne de uma concepção protetiva do indivíduo, já a liberdade positiva como faculdade de ação ${ }^{6}$. Ora, nesse sentido Berlin indica a liberdade política como garantia ao indivíduo, e mais, como determinação do Estado de fazer o bem comum se justificar pela adesão à racionalidade como busca de manter a própria autonomia. Diz Berlin ${ }^{7}$ :

Minha defesa da liberdade irrestrita pode algumas vezes, prima facie, não harmonizar-se com a defesa da liberdade irrestrita feita por outra pessoa; mas a solução racional de um problema não pode colidir com a solução igualmente verdadeira de outro problema, pois duas verdades não podem ser incompatíveis do ponto de vista da lógica; portanto, uma ordem justa precisa, em tese, ser discernível ${ }^{8}$ - uma ordem cujas normas possibilitem soluções corretas para todos os problemas que possam vir a surgir em seu âmbito (...) Racionalidade é conhecer as coisas e as pessoas pelo que elas são (...)"

A liberdade de contrato, segundo Berlin ${ }^{9}$, se afasta da tradição de um mercado que sujeita o indivíduo ao Estado em Hobbes e atinge em Rousseau a meta de uma autonomia pública $^{10}$.

Não basta seguir a autonomia burguesa assegurada pelo Estado Moderno, porém é na motivação da racionalidade autônoma que se constrói a liberdade que possibilitará a construção de todos os valores, inclusive os do espaço público, do uso público da razão contra todas as tiranias, presentes na história da Modernidade em seus personagens individualistas absolutistas ou antiéticos e autoritários tais como Napoleão, Robespierre etc.

O aspecto econômico do ideário liberal se firmou com Adam Smith, economista inglês que pregava a não intervenção do Estado na atividade econômica, por crê existirem leis impessoais que regeriam as ações econômico-financeiras, que os indivíduos livremente descobririam na pragmática mercadológica. Outros economistas ampliaram essas ideias (David Ricardo, Say, Malthus etc).

O liberalismo como ideário comum ao campo político e econômico seria unificado no pensamento de John Stuart Mill, um pensador inglês da primeira metade do século XIX, ao coordenar o utilitarismo de Jeremy Bentham e sua defesa da felicidade como obtenção do prazer individual para o maior número de pessoas possível, o liberalismo da livre-iniciativa de Smith e sintetizar os ideais de liberalismo politico da liberdade de expressão, pensamento e de critica do iluminismo.

Mill apostou na livre iniciativa, na busca da felicidade e criatividade pessoais, e demonstra que o ideário liberal passa a ser um conjunto doutrinário coeso, em que a política 
se torna produto da defesa de bandeiras de autonomia e de independência dos indivíduos.

$\mathrm{O}$ que defendemos como Direito liberal em um sentido clássico é sintetizado no pensamento de Mill, que defendeu o utilitarismo com o princípio da felicidade para o maior número, vinculou a liberdade ao valor hedônico, mas não se fixou nesse hedonismo - Mill buscou valores mais profundos, humanitários, pois Bentham não fugiu do princípio da utilidade hedônica individual para migrar a outros valores necessários, saindo de um conceito de prazer humano mais integral do que o prazer corporal. "É melhor ser uma criatura humana insatisfeita que um porco satisfeito; é melhor ser Sócrates insatisfeito do que um tolo satisfeito"11.

Os utilitaristas se preocuparam com ações exteriores, que tenham significado prático de bondade, disposições mentais ou abstratas éticas não servem ao utilitarista ${ }^{12}$, Mill ${ }^{13}$ se preocupou com o sofrimento humano: $95 \%$ dos homens são infelizes pela escravidão, pela miséria e opressão. Isso o levou ao liberalismo igualitarista em luta por direitos. Todos os homens tem o direito a reclamar a felicidade e a igualdade, a menos que uma conveniência social coloque o contrário.

Justiça, mais do que uma conveniência individual, mas condutas que devam ser praticadas conforme uma utilidade social absoluta, o que a torna a parte mais importante da moral. O sentimento de justiça surge a partir do desejo de vingança e da necessidade de simpatia para com os indivíduos injustiçados ${ }^{14}$, o reclamo moral da justiça faz com que um indivíduo possa exigir o que lhe é devido de outrem, isso está pressuposto em todo o Direito como uma realidade empírico-sentimental, não é junaturalismo. O utilitarismo se relativiza frente ao justo, onde a moral se torna dominante para o bem maior da sociedade. É o hábito de ser justo que torna a sociedade mais suportável, a simpatia entre os homens é motivada pela relação de respeito entre eles.

A perspectiva de Mill sobre a proteção da liberdade política assumiu já precocemente, quando defendeu as bandeiras das minorias, como o anti-escravagismo e o feminismo, bem como a defesa inicial de direitos trabalhistas, as transformações intestinais na sociedade em fins do século XIX fizeram que um progressismo, principalmente por parte dos socialistas, pressionasse o sistema liberal parlamentar de voto censitário e de uma concepção jurídica patrimonialista individualista (supervalorização da propriedade privada e de seu uso pelo detentor do domínio ou posse), rumo a modificações em alguns pontos de seu ideário, primacialmente no espectro político, e no final do séc. XIX e início do séc. XX, o liberalismo assimilou bandeiras como o voto extensivo às classes proletárias e médias, as eleições não censitárias etc.

O liberalismo econômico, entretanto, continuava a firmar-se na livre concorrência e no não-intervencionismo estatal como vigas mestras de seu programa.

Com o crescimento incontrolável da especulação financeira em fases primaciais do século XX, produto inevitável do acúmulo de capitais, o financismo imperante drenou recursos que seriam de investimentos e, aliado a um excesso de moeda e de produção no mercado, bem como da escassa capacidade de consumo da população, ocasionou uma valorização irreal de ações das empresas, que então quebraram, devido à irrealidade de suas ações nas bolsas de valores de todo o mundo, e por outro lado devido à parca vendagem, devido à concentração de renda absurda nas mãos de poucos. Foi a crise de 1929, a maior de toda a história do capitalismo. As consequências da crise se deram mais gravemente porque um círculo vicioso foi formado: as empresas quebravam porque não vendiam e não vendiam porque não havia poder de consumo entre as classes mais modestas, dada a concentração do capital.

Foi o economista inglês John Maynard Keynes quem propôs a solução adotada pelos governos da época para a problemática: a intervenção estatal na economia, não simplesmente da maneira que o governo de Edgar Hoover (1928-1932) havia realizado nos 
EUA num primeiro momento de impacto da crise, porém de modo estritamente calculado. Ações controladoras da política monetária, restringindo a emissão de moeda; com vultosas políticas de geração de emprego por parte do Estado; com controle do câmbio, pondo fim ao livre-cambismo etc., esses os pontos-chave do estatismo keynesiano.

A partir das exigências sociais do pós-II Guerra Mundial, o que se traduz num valor político que se forma numa liberdade coletiva na possibilidade de uma liberdade construída republicanamente (publicamente e legalmente, no sentido kantiano de republicanismo político) e não apenas egoisticamente, no projeto capitalista de mercado competitivo. $\mathrm{O}$ liberalismo e a razão pública como expressão do interesse coletivo nem sempre se mostram conformes, mas o esforço de um diálogo é possível a partir das linhas republicanas em Kant e Rousseau, conforme Berlin ${ }^{15}$ :

Aqueles que acreditavam na liberdade como num autogoverno racional mais cedo ou mais tarde com certeza iriam refletir a respeito de como isso se aplicaria não apenas à vida interior de um homem, mas também ao relacionamento com outros membros de sua sociedade. Mesmo os mais individualistas dentre eles - E Rousseau, Kant e Fichte certamente começaram como individualistas- chegaram a um ponto em que se indignaram a si mesmos se era possível existir uma vida racional não apenas para o individuo, mas também para a sociedade, e, em caso positivo, de que forma poderia ela ser conseguida. Desejo ser livre para viver minha vontade (ou meu "eu real") ordena, mas outros também o desejam. Como evitar conflitos com as vontades dos outros ? (...) Um Estado racional (ou livre) seria um Estado governado por leis que todos os homens racionais acatariam livremente; (...)

\section{A proposta liberal, o estatismo do Estado Social e a Teoria Crítica DA ESCOLA DE FrANKFURT}

O Estado "liberal clássico" é finalisticamente mecanicista, é um Estado-meio que serve ao indivíduo, por ser originado em sua liberdade. $\mathrm{O}$ objetivo do liberalismo é buscar a finalidade do Estado na possibilidade das liberdades externas conviverem, asseguradas pela lei e, caso descumprida a norma, asseguradas pela coerção, como colocou o próprio Kelsen $^{16}$.

Wilhelm von Humboldt definiu muito bem o individualismo como acepção valorativa política ao dizer que o fim do Estado é o indivíduo. Essa é a linha que melhor representa a tradição liberal de Política na vertente kantiana. Em uma acepção individualista de Política, o Estado serve a um Direito cuja expressão singular é a defesa da liberdade. " $L a$ acción del Estado deve limitarse tanto como para que no se perjudique el perfeccionamiento del individuo" 17 , diz Joaquín Abellan em seu estudo preliminar sobre a obra "Os limites da ação do Estado" de Wilhelm von Humboldt.

A liberdade como valor implica, pois, no campo moral e no campo jurídico-político, um valor universal a priori, que unifica o movimento liberal em sua pluridiversidade de manifestações quando se encara, segundo Kersting ${ }^{18}$, o substrato natural de incidência dos direitos humanos sem uma retórica inflacionária dos mesmos e sem demagogia política; liberdade é uma faculdade da vontade do indivíduo natural para Kersting ${ }^{19}$, base das concepções que projetam o valor da pessoa humana, e que é o objeto da tutela acerca dos direitos humanos universais que constituem o núcleo de qualquer sistema político que se pretende democrático na atualidade.

Para Habermas, o conceito a pessoa humana é o núcleo do próprio Direito Internacional, é o sujeito privilegiado de direitos humanos internacionais e não mais os Estados $^{20}$. Após as agruras da II Guerra Mundial a pressão para a justificação filosófica do 
humanismo que proteja a individualidade faz-se inafastável como exigência política. Hegel e Marx e seus asseclas político-filosóficos reduziram os seres humanos a meros peões no jogo comandado pelo Estado.

Hegel, ao abarcar toda a realização de liberdade no próprio ente estatal, esperando no Estado a realização da razão emancipadora ${ }^{21}$, que a nosso ver produziu o crescimento do próprio poder do Estado no século $\mathrm{XX}^{22}$; e os marxistas com a ideia de usar o ser humano em um projeto político de emancipação que já produziu tantos desastres anti-humanitaristas por ditaduras totalitárias que puseram em dúvida a sentido de "libertação social" baseado no materialismo histórico-dialético em seu significado político. O próprio Marx havia proclamado na "Questão Judaica'23, que antes de emancipar os outros, deveríamos emancipar a nós mesmos. Essa obrigação moral remete diretamente na tradição kantiana ao problema da emancipação moral pelo auto-esclarecimento e uso da razão. A tradição marxista encaminhará sua visão coletivista e sócio-histórica a uma luta política revolucionária e quererá substituir a tradição liberal e reflexiva kantiana por uma tradição de ação política.

A "sociável insociabilidade" de Kant ${ }^{24}$ indica precisamente a capacidade que devemos ter de entrar em conflito com o outro sem destruí-lo. A ideia antropológica do dissenso encaminha Kant a uma posição política naturalmente liberal, ao ovacionar o conflito e a disputa entre os homens como algo saudável à espécie humana como um todo, inclusive historicamente o antagonismo e a discórdia entre os homens geram progresso ${ }^{25}$.

Para Kant, "os homens serão em parte sempre egoístas" como interpreta Kolm, mas isso integra as considerações práticas da regulação da vida social ${ }^{26}$. Para Kant, no Estado republicano é possível pensar a mitigação do egoísmo, assim como na federação internacional é possível pensar na mitigação dos conflitos pela instauração de um conjunto de leis que visem a paz entre os povos federados. Se a orientação coletivista dirigir o Estado $^{27}$, instituição que agrega socialmente o poder, fim para o qual foi constituída, este verá um crescimento incontrolável de seu poder, é o que indica a História ${ }^{28}$.

Se o bem comum, na linha do pensamento liberal, é principalmente o exercício da liberdade por cada indivíduo de buscar para si a defesa de seus interesses ${ }^{29}$, e se o fim da sociedade é a concretização da individualidade, a super afetação do social, tal qual defende o organicismo, é uma deturpação da própria diretriz axiológica pressuposta ao valor social e será também um desvirtuamento do escopo do próprio valor político; pois gerará superabundância de poder e se voltará contra a limitação que lhe impõe o dever de proteção e garantia da liberdade dos cidadãos. Mesmo que os indivíduos assim deliberassem em prol do coletivo, sofreriam com o tempo as consequências, como já sofreram quando sempre, no campo histórico, colocaram o coletivo sobre o particular de um modo absoluto (como no totalitarismo, aponta $\operatorname{Arendt}^{30}$ ), transferindo sua liberdade para o Estado ${ }^{31}$.

Para Rawls ${ }^{32}$, a tarefa de uma promoção de igualdade será levada a cabo através da implementação estatal de direitos mediante a ação judicial da corte constitucional concretizante dos princípios constitucionais que buscam a igualdade ${ }^{33}$, que para ele é o núcleo de proteção mais poderoso contra o ataque a direitos fundamentais e o mecanismo de interpretação ampliada dessa proteção estatal aos indivíduos discriminados. Kant, com seu conceito de "reformismo constante" entende o liberalismo como projeto de legislação não acabada, de responsabilidade de cada um ao usar sua autonomia ${ }^{34}$; a opção de Kant é a favor do Direito, não da "vontade geral" expressa como poder público, mas de sua expressão no parlamento, portanto do espaço público e do poder legislativo (representativo) ${ }^{35}$.

Essa visão autonomista de democracia liberal de Kant é esposada por Nozick. Para uma concepção radical de liberalismo como a de Nozick, só existem indivíduos e não coletividades ou virtudes públicas ${ }^{36}$. Na tradição liberal próxima a de Kant, Nagel ao analisar o pensamento de Nozick também proporá uma fundamentação do Estado a partir 
ideia de que a liberdade antecede o Estado e se relaciona a valores, a discussão do papel do sujeito passa pela discussão de sua posição axiológica e sua relação com o Estado, como diz $\mathrm{Nagel}^{37}$, analisando Nozick.

A posição de um "Estado mínimo" defendida por Nozick, é conhecida por defender uma visão de intervenção mínima do Estado na vida privada, centrar na questão da segurança pública a prestação de ações governamentais para o cidadão, ater-se, portanto, ao fato do oferecimento de uma base jurídica da existência cidadã. $\mathrm{O}$ mecanismo de defesa do cidadão contra agressões externas, portanto, é a grande perspectiva apontada por Nozick. Mas a defesa do cidadão é também a defesa contra o próprio Estado e não apenas contra o que está fora dele. O que está em questão é, além da segurança, a liberdade, que uma vez cedida ao Estado para proteção, pode ser atingida pelo próprio Estado pelo exercício do seu poder.

Como pode então o Estado autolimitar-se se lhe foi concedido um poder integral de zelar pela segurança do cidadão? As duas posições que Nagel analisa a partir de Nozick, são paradigmáticas no sentido de mostrar que os direitos individuais são concessões desse ente controlador da sociedade que é o Estado, ou são os direitos individuais expressões de direitos naturais preexistentes, como em Locke.

Nagel $^{38}$ diz que Nozick está certo em admitir a segunda solução, a de Locke, frisa, assim, que o caráter pré-estatal dos direitos individuais deve ser reconhecido e não apenas a possibilidade de exercer direitos no âmbito do Estado, mas o ponto de proximidade de Nozick com nossa visão sobre Kant seria exatamente o de admitir que deve haver a possibilidade de opor direitos ao Estado, na linha que defendemos de interpretação de Kant, a função da liberdade política é crucial para a compreensão do papel do Estado: um ente que serve à defesa dos indivíduos e não absoluto em sua função de exercício de poder, porque existe uma ordem de direitos anterior ao mesmo, direitos que o fundamentam e originam. $\mathrm{O}$ Estado pode favorecer a partir de si a possibilidade de projeção de direitos individuais, apenas não pode deixar de reconhecer a primazia do cidadão e sua liberdade política em relação e ele mesmo (o Estado), que é o que Habermas afirmará como sendo a liberdade positiva de direitos de participação e de comunicação ${ }^{39}$.

Liberdade política individual e República constitucional são interdependentes no âmbito do Estado racional de Kant, Habermas aproveita essa tensão transformando as duas vertentes da política por meio de uma complementaridade crítica e dialética, que será sustentada como democracia deliberativa e instrumentalizada via procedimentalismo constitucional, no intuito de apoiar as pretensões remanescentes da "Teoria Crítica" de apontar os déficits de legitimidade democrática no capitalismo tardio.

A "Teoria Crítica" e sua visão abrangente de uma sociedade que não suporta o nível de alienação, despersonalização e desvalorização da razão como aponta Adorno, precisa ser levada em conta pela política, isso revela a possibilidade de o ideário liberal clássico e sua defesa da individualidade e da liberdade pessoais serem tratados criticamente pela teoria sócio-política : diante do fato da despersonalização e da crise da razão discursiva pelo assomar da razão técnica e instrumental, é impossível fazer um discurso racional liberal num sentido igual ao do século XVIII, diante de "Auschwitz" como disse Adorno, não se pode mais ser otimista e fazer "poesia", não se pode mais apostar na emancipação pela simples utilização do esclarecimento de um modo amplo.

\section{HABERMAS ENTRE A LIBERdAde E A REPÚBLICA: UM DIÁLOGO CONSTRUTIVO COM O Liberalismo a PARTIR do Estado Democrático de Direito}

A missão do liberalismo como defesa da liberdade individual e redução do papel do 
Estado na política e na economia não pode ser olvidada: pensar a tradição liberal é se manter nessa finalidade. Todavia, o impacto da "Teoria Crítica" em pensadores como Habermas, que assimila a perspectiva de uma renovação dessa tradição que modela o marxismo a um perfil de crítica ideológico-cultural, poderia levar a uma completa dissociação e até mesmo combate ao liberalismo, inclusive considerando-o uma ideologia derivada ou associada ao capitalismo.

Assim, poderia em um primeiro momento se pensar na dificuldade que é discutir o Direito Liberal à luz do pensamento habermasiano enquanto herdeiro da "Teoria Crítica"; todavia, Habermas com sua virada linguística e pragmática a partir da década de 70 do século XX, aproxima-se de uma acepção de democracia participativa e constitucional e afasta-se do "socialismo real", do comunismo e da teoria politica clássica do marxismo, considerando-a metafísica em aspectos centrais, como no maniqueísmo da "luta de classes" ou na utopia da "ditadura do proletariado". Nas sociedades do "socialismo real" não se constituíram esferas públicas onde os projetos políticos pudessem ser debatidos, sendo impostos pela burocracia estatal.

Para Habermas, os grandes conceitos da tradição marxista ficaram obsoletos diante do pluralismo metodológico da pós-modernidade e da ideia de uma linguagem que justifica a política somente se puder ser interpretada por uma comunidade de falantes pressupostamente livres e não vinculados a Estados autoritários, ou a projetos de emancipação política que não admitam a crítica a seus próprios pressupostos de linguagem, o que é mais plausível que possa ocorrer em sociedades pós-metafísicas democráticoliberais.

A partir de um pensamento pós-metafísico em que valoriza a significação prática da linguagem, e conseguintemente da linguagem política, Habermas reconsidera posições marcadas de profundo caráter não histórico e não democrático-constitucional do marxismo e pensa que a função crítica da teoria filosófica deve fincar suas bases e instrumentais em uma teoria da ação, que se regule pela significação que a comunidade dos falantes lhe conceder e que possa ter como fim prático da ação política a vida concreta (Lebenswelt) historicamente situada.

O "socialismo real" parece ter traído suas vinculações de perspectiva histórica e partiu para uma modelagem não prática e não vinculada às comunidades nas quais se desenvolveu, aplicando uma teoria que se tornou autoritária em sua efetivação pela burocracia dos Estados nos quais se manifestou historicamente no século XX.

Esse autoritarismo do "socialismo real" levou Habermas a se aproximar de uma visão democrática e liberal principalmente olhando para os modelos anglo-saxão e alemão, de onde depreende do primeiro exatamente a tradição de respeito às liberdades individuais e de lutas civis e um fundo de inspiração por direitos humanos, e do segundo absorve a estrutura de pensamento sobre o Estado de Direito e o republicanismo.

Habermas, ao abordar o liberalismo, parte da caracterização do seu irmão jusfilosófico, o contratualismo, a forma de um legítimo direito fundado na laicidade do contrato devido ao esgotamento do potencial legitimador do Direito natural de espeque religioso $^{40}$. O contratualismo e seu pacto de liberdade racional substitui o Direito natural religioso pelo artifício racional do contrato, e o liberalismo emerge como ideário de legitimação política laica, confiante na ação dos sujeitos no mercado e no controle do poder estatal, o liberalismo se legitima no aspecto prático na economia e não na Metafísica política (como o fazem o conservadorismo de matriz religiosa ou o socialismo revolucionário, o primeiro por confiar nos potenciais de legitimação de valores metafísicos e o segundo por apostar na utopia política como guia da ação política prática).

Já na esfera de um agir comunicativo a exigência de institucionalização do poder desfere limitações ao mercado: só há potencial de legitimação comunicativa pela via da 
institucionalização no Estado de esferas de comunicação que propiciem o entendimento e não a estratégia dos interesses mercadológicos plenos ${ }^{41}$. A própria ordem estatal exige limitações ao mercado, em razão da necessidade de proteger interesses nacionais (como a segurança nacional) e formar uma esfera pública ${ }^{42}$.

A lógica liberal da divisão dos poderes já não legitima o Direito em sua acepção mais ampla, depende de uma conformidade com os potenciais comunicativos insertos na sociedade. $\mathrm{O}$ poder administrativo baseado na lei deve ser justificado à luz da razão comunicativa que trabalha na pluralidade de valores na sociedade. Habermas ${ }^{43}$ aponta a legitimidade do Direito liberal como decorrente do processo comunicativo de formação da vontade política e sua capacidade de institucionalização no Estado de Direito. O papel do parlamento como expressão da vontade política e a ação do judiciário são elementos dinâmicos que se movimentados via racionalidade comunicativa são importantes meios de alargamento da democratização do Estado administrador ${ }^{44}$.

Para Habermas, os modelos socialista e burguês de Direito que emergem como divergentes no século XX são trabalhados complementarmente por um meio democráticoprocedimentalista - a razão comunicativa que é exigida pelos modelos sociais ou liberais estatais como critério de legitimação pós-moderno depende da institucionalização estatal de procedimentos linguístico-discursivos elaborados pelos cidadãos em suas pretensões sociais ou liberais de poder ${ }^{45}$. A legitimação do Direito liberal deve se sustentar, para Habermas, na abertura discursiva da participação do cidadão nos processos de poder do Estado, bem como na abertura intersubjetiva do judiciário a uma participação do cidadão nas decisões Habermas ${ }^{46}$ defende isso como base das teorias procedimentalistas e intersubjetivistas da jurisdição constitucional contra o solipsismo do juiz liberal de Ronald Dworkin. Ao invés de preconizar um ideal de personalidade do juiz, como o "Juiz Hércules" de Dworkin, Habermas ${ }^{47}$ mostra que o que democratiza o Direito liberal é a comunicação do Direito com a sociedade, por via de uma racionalidade comunicativa e procedimentalista. Reproduzindo as críticas de Michelman, Habermas ${ }^{48}$ alega que o "Juiz-Hércules" é um juiz virtuoso "heróico" e monológico, e que o ideal de uma democratização do judiciário é assimilar regras comuns discutidas como um programa normativo aberto a todos os cidadãos e não apenas aos experts do Direito.

A busca do cidadão liberal de sua liberdade negativa de cobrar do Estado o respeito por seus interesses, deve se confrontar a uma postura republicana de assimilação de posturas axiológicas orientadas pela comunidade e suas perspectivas de formação de uma virtude comum $^{49}$. Habermas pensa que a comunidade real e suas projeções de valores são prisioneiras de um fundo tradicionalista, que não gera entendimento comunicativo intersubjetivo e suficientemente argumentativo para fins de uma política radicalmente democrática $^{50}$. A democracia deliberativa ser pensada como uma comunidade virtual de cidadãos comunicativos e o tribunal constitucional deve assumir uma postura ativista de defesa da Constituição, mas que não feche a abertura procedimental e comunicativa com a comunidade de comunicação ideal deliberativa ${ }^{51}$. Habermas critica a posição liberal de estratégias individuais de busca de interesses pelos cidadãos, mas não aceita a postura republicana de confiança completa na comunidade por confundir a autonomia privada com a pública.

Para Habermas, a divisão dos poderes (executivo, legislativo e judiciário) é ressignificada não como substituição pelo judiciário da função normatizadora do legislador, mas complementar ao parlamento, principalmente na defesa do núcleo da Constituição, que é a proteção dos direitos fundamentais dos cidadãos. Assim, a ideia liberal de uma liberdade negativa que se exige do Estado, é complementada por uma liberdade positiva como direito à participação e a comunicação ${ }^{52}$. A radicalização da democracia deliberativa é que a participação política comunicativa do cidadão possa institucionalizar direitos perante o 
Estado $^{53}$ dentro de um processo inclusivo de formação de opinião e vontade política, que por isso é procedimental como postura aberta das instituições ao processo comunicativo decorrente da política e não preso a valores éticos de formação de virtudes políticas nas comunidades (como quer Michelman) ${ }^{54}$, nesse ponto Habermas se aproxima de Cass Sustein e seu modelo de republicanismo deliberativo e procedimental, que forma o entendimento político no próprio processo jurídico-democrático e não diretamente na ética comunitarista.

\section{Conclusão}

A crise do liberalismo político é representada pela continuidade do seu compromisso com a pressão mercadológica, que seria o campo de ação privilegiado da formação criativa dos indivíduos como expõe Mill e de ação de poder da vida privada como defendem Kant, Hobbes e Locke (seção 1). O Estado liberal foi acossado pelo Estado Social dada a necessidade de construção de políticas públicas devido à crise do capitalismo, a recomposição de legitimidade veio da defesa de um paradigma igualitário, por exemplo com Rawls (com sua proposta de pluralismo razoável como tolerância política e de ações afirmativas estatais). A "Teoria Crítica" da Escola de Frankfurt apontou a alienação do mercado sobre a ação política do indivíduo, Habermas absorveu essa crítica almejando desconstruir a colonização da Política pela economia através da radicalização da democracia liberal pela adoção do ideal constitucional republicano da autonomia pública, não mais presa ao formalismo da divisão de poderes clássica do Estado liberal, mas pela democracia deliberativa através da argumentação dos cidadãos (uso da razão como processo político comunicativo) perante o Estado (institucionalização de pretensões de legitimidade normativa), levando-o a resguardar direitos fundamentais pelo judiciário ao concretizar as garantias constitucionais. Habermas defende uma política construída pelo procedimento linguístico-discursivo, laica e republicano-constitucional, valoriza as liberdades individuais sem recair na mística eticizante do poder, já que Direito e Ética são co-originais não há hierarquia entre eles, nem uma esfera política de valor em que o Bem supere o jurídicoinstitucional. Há uma compatibilidade entre a democracia deliberativa laica e o liberalismo, desde que este minimize via razão comunicativa intersubjetiva o agir estratégico, abrindo as instituições ao procedimento construtivo decorrente da autonomia política deliberativa, onde o constitucionalismo deve ser um processo democrático-participativo via razão comunicativa pública e não paternalista.

\section{REFERÊNCIAS}

ARENDT, H. O sistema totalitário. Tradução Roberto Raposo. Lisboa: Dom Quixote, 1978.

BERLIN, I. Quatro ensaios sobre a liberdade. Brasília: EDUNB, 1981. Rousseau e outros cinco inimigos da liberdade. Lisboa: Gradiva, 2005.


bounded world. New York: Cambridge University Press, 2011.

GIESEN, K. G. Habermas, a segunda modernidade e a sociedade civil internacional. In: Novos Estudos do Cebrap, jul., n. 60, p.87-97, 2001.

HABERMAS, J. Direito e Democracia: entre facticidade e validade. Tradução Flávio Beno Siebeneichler. Rio de Janeiro: Tempo Brasileiro, 1997, vol.1.

HEGEL, G.W.F. Linhas Fundamentais da Filosofia do Direito ou Direito Natural e Ciência do Estado em Compêndio. Tradução Paulo Meneses et al. São Paulo: Loyola-UnisinosUnicap, 2010.

HOBBES, T. Leviathan ou matéria, forma e poder de um Estado eclesiástico e civil. São Paulo: 
Martins Fontes, 2014.

HUMBOLDT, W.V. Los limites de la acción del Estado. Estudo preliminar Joaquín Abellán. Madrid: Tecnos, 2002.

KANT, I. A Metafisica dos Costumes. Princípios metafísicos da doutrina do Direito. Tradução José Lamego. Lisboa: Fundação Calouste Gulbenkian, 2005. . Antropologia de um ponto de vista pragmático. São Paulo: Iluminuras, 2006.

KANT, I. Ideia de uma História Universal de um ponto de vista Cosmopolita. São Paulo: Martins Fontes, 2003.

KELSEN, H. Teoria Pura do Direito. Tradução João Baptista Machado. Coimbra: Armênio Amado, 1984.

KERSTING, W. Universalismo e direitos humanos. Porto Alegre: EDPUC-RS, 2003.

KOLM, S.C. Teorias Modernas da Justiça. Tradução Jefferson Luis Camargo e Luis Carlos Borges. São Paulo: Martins Fontes, 2000.

MARX, K. A questão judaica. Tradução Silvio Donizete Chagas. São Paulo: Centauro, 2002.

NAGEL, T. Otras Mentes. Ensayos críticos (1969-1994). Tradução Sandra Girón. Barcelona: Gedisa, 2000.

NOZICK, R. Anarquia, Estado e Utopia. São Paulo: Martins Fontes, 2011.

RAWLS, J. Justiça e democracia. São Paulo: Martins Fontes, 2004.

. O liberalismo político. São Paulo: Martins Fontes, 2012.

ROUSSEAU, J. J. Do contrato social. Tradução Eduardo Brandão. São Paulo: Penguin, 2011.

SOROMENHO-MARQUES, V. História e Política no pensamento de Kant. Sintra: EuropaAmérica, 1994.

STUART MILL, J. A liberdade. Utilitarismo. Tradução Eunice Ostrensky. São Paulo: Martins Fontes, 2000.

WEIL, E. Hegel e o Estado. São Paulo: Érealizações, 2011.

\section{Notas}

1 HOBBES, T. Leviathan ou matéria, forma e poder de um Estado eclesiástico e civil. São Paulo: Martins Fontes, 2014, p.18-19.

2 HOBBES, T. Op. Cit. p.85.

3 HOBBES, T. Op. Cit. p.112.

4 SOROMENHO-MARQUES, V. História e Politica no pensamento de Kant. Sintra: EuropaAmérica, 1994, p.124.

5 BERLIN, I. Quatro ensaios sobre a liberdade. Brasília: Ed. da UNB, 1981, p.147.

6 BERLIN, I. Quatro ensaios sobre a liberdade. Brasília: Ed. da UNB, 1981, p.149.

7 BERLIN, I. Op. Cit.p.152-153.

8 BERLIN, I. Op. Cit.p.102.

9 BERLIN, I, Quatro ensaios sobre a liberdade. Brasília: Ed. da UNB, 1981, p. 102.

10 Para Berlin o republicanismo radical de Rousseau nega a liberdade em seu valor em si referida ao sujeito e suas escolhas, o arbítrio é considerado dissuasivo da unidade estatal na busca pelo bem comum. Cf. Berlin em Rousseau e outros cinco inimigos da liberdade. Lisboa: Gradiva, 2005, p.78. Diz Rousseau em Do contrato social. Tradução Eduardo Brandão. São Paulo: Penguin, 2011, p.165: "O cidadão dá seu consentimento a todas as leis, inclusive àquelas que são aprovadas contra sua vontade e àquelas que o punem se ele ousar violar uma. A vontade constante de todos os membros do Estado é a vontade geral; é por ela que eles são cidadãos livres." Nessa passagem Rousseau frisa o compromisso com a legalidade do Estado, a integridade do pacto político. Nesse ponto não se poderia cogitar de uma negação da liberdade, mas sua existência na vida jurídica de um Estado de leis. Todavia, Rousseau imprime em importantes passagens o caráter finalístico de uma democracia republicana: "Uma constituição sadia e forte é a primeira coisa que é preciso buscar..." (ROUSSEAU, 2011, p.100), e a vontade particular e os interesses singulares devem ceder aos interesses e vontade geral que é indestrutível: "Cada um, separando seu 
interesse do interesse comum, vê que não pode separá-lo inteiramente, mas sua parte do mal público não lhe parece nada junto ao bem exclusivo de que pretende se apropriar. Tirante esse particular, ele deseja o bem geral em seu próprio interesse mais fortemente do que qualquer outro" (ROUSSEAU, 2011, p.162). Nessa última passagem poder-se-ia concordar com Berlin ao defender uma fundamentação republicana radical em Rousseau, com a predominância da vontade geral sobre a particular em Rousseau, o que leva a uma ideia de não-liberdade individual, mas de liberdade da vontade coletiva.

11 STUART MILL, J. A liberdade. Utilitarismo. Tradução Eunice Ostrensky. São Paulo: Martins Fontes, 2000, p. 191.

12 STUART MILL, J. Op. Cit. p.207.

13 STUART MILL, J. Op. Cit. 208ss.

14 STUART MILL, J. Op. Cit. p.256.

15 BERLIN. I. Quatro ensaios sobre a liberdade. Brasília: Ed. da UNB, 1981, p.151-152.

16 KELSEN, H. Teoria Pura do Direito. Tradução João Baptista Machado. Coimbra: Armênio Amado, 1984, p.34.

17 HUMBOLDT, W.V. Los limites de la acción del Estado. Estudo preliminar Joaquín Abellán. Madrid: Tecnos, 2002, p. XVII.

18 KERSTING, W. Universalismo e direitos humanos. Porto Alegre: Ed da PUC-RS, 2003, p. 68.

19 KERSTING, W. Universalismo e direitos humanos. Porto Alegre: Ed da PUC-RS, 2003, p.69.

20 GIESEN, K. G. Habermas, a segunda modernidade e a sociedade civil internacional. In: Novos Estudos do Cebrap, jul., n. 60, p.87-97, 2001.

21 HEGEL, G.W.F. Linhas Fundamentais da Filosofia do Direito ou Direito Natural e Ciência do Estado em Compêndio. Tradução de Paulo Meneses et al. São Paulo: Loyola-UnisinosUnicap, 2010, p.56.

22 WEIL, E. Hegel e o Estado. São Paulo: Érealizações, 2011, p.55, Hegel considera o Estado a realização do Espírito Absoluto na História.

23 MARX, K. A questão judaica. Tradução Silvio Donizete Chagas. São Paulo: Centauro, 2002, p. 15 .

24 KANT, I. Ideia de uma História Universal de um ponto de vista Cosmopolita. São Paulo: Martins Fontes, 2003, p.8.

25 KANT, I. Ideia de uma História Universal de um ponto de vista Cosmopolita. São Paulo: Martins Fontes, 2003, p.8.

26 KOLM, S.C. Teorias Modernas da Justiça. Tradução Jefferson Luis Camargo e Luís Carlos Borges. São Paulo: Martins Fontes, 2000, p.258. Num sentido comum Kant e Stuart Mill para Kolm (Op. Cit. p.308) condenam a inveja, mas a tomam como um produto pragmaticamente incontornável da natureza humana, aproveitando-a para a função de obrigar a sociedade política criar as condições de igualdade. Kant em Antropologia de um ponto de vista pragmático. São Paulo: Iluminuras, 2006, p.181ss, parte do caráter empírico da personalidade humana objetivando contextualizá-la em uma forma de atuação que vise a descrição (observação) do caráter humano para que posteriormente ele possa ser repensado em função dos princípios racionais. Essa observação de Kolm sobre o significado para a justiça da antropologia de Kant a apresenta como de fato é - racional e pragmática, jamais idealista.

27 KANT, I. A Metafísica dos Costumes. Princípios metafísicos da doutrina do Direito. Tradução José Lamego. Lisboa: Fundação Calouste Gulbenkian, 2005, p.15.

28 RAWLS, J. O liberalismo politico. São Paulo: Martins Fontes, 2012, p.567, usa o argumento contrário: a História mostra a eficácia do liberalismo como ideário protetor da Democracia.

29 RAWLS, J. Justiça e democracia. São Paulo: Martins Fontes, 2004, p. 155: o papel das liberdades políticas é, sobretudo, um instrumento que preserva as outras liberdades. Para Rawls (2004, p.154) na tradição liberal, como em Constant, a liberdade de pensamento parece ser mais importante que a política, como uma qualidade superior, mas isso decorre de uma avaliação virtuosa como um posicionamento moral, não racional no sentido de não neutralidade. Kant diz isso na Ideia de uma História Universal de um ponto de vista Cosmopolita. São Paulo: Martins Fontes, 2003, p.18: "Se se impede o cidadão de 
procurar seu bem-estar por todas as formas que lhe agradem, desde que possam coexistir com a liberdade dos outros, tolhe-se assim a vitalidade da atividade geral e com isso, de novo, as forças do todo. Por isso as restrições relativas à pessoa em sua conduta são paulatinamente retiradas e a liberdade universal de religião é concedida; e assim surge aos poucos, em meio a ilusões e quimeras inadvertidas, o Iluminismo (Aufklärung) como um grande bem que o gênero humano deve tirar mesmo dos propósitos de grandeza egoísta de seus chefes, ainda quando tenha em mento só as próprias vantagens. Mas este Iluminismo, e com ele também um certo interesse do coração do homem esclarecido (aufgeklärt) não pode deixar de ter em relação ao bem, que ele concebe perfeitamente, precisa aos poucos ascender até os tronos e ter influência mesmo sobre os princípios de governo".

30 ARENDT, H. O sistema totalitário. Tradução Roberto Raposo. Lisboa: Dom Quixote, 1978, p. 433 ss.

31 Isso nos aproximaria de uma visão de um liberalismo sem compromisso com o Estado e sua proteção publicista de direitos, como defende a "Escola Austríaca" de Mises e Hayek, mas a exigência da razão de um ponto de vista público emerge a confluência ao Estado como ponto de busca de igualdade, e não apenas de liberdade individual, que seria destruída diante de crises econômicas como a de 1929, sem a visão englobante de sua própria proteção que o Estado deve assegurar. Por isso acreditamos que o liberalismo deve dialogar com as vertentes liberais sociais e social-democratas, daí a necessária aproximação do liberalismo com o pensamento de Habermas e do pensamento deste com liberais sociais como Rawls, Nagel, Rorty e Dworkin.

32 RAWLS, J. O liberalismo político. São Paulo: Martins Fontes, 2012, p.57.

33 Como o modelo de sistema jurídico de Kant não prevê um tribunal constitucional, não se pode conceber que a ideia de igualdade pudesse ser tutelada a não ser em pretensões individuais. A questão da propriedade só poderia ser regida por um debate público, mas de qualquer forma se limitando ao conceito de propriedade jurídica, que organiza a posse. Assim, pretensões empíricas sobre a propriedade "injusta" ou excessiva de terras, por exemplo, em detrimento de terceiros, seriam reconstruídas pela ideia de uma judicialização de demandas que teria que ser tutelada à luz da lei e no sentido protetivo da posse privada, Kant na A Metafisica dos Costumes. Princípios metafisicos da doutrina do Direito. Lisboa: Fundação Calouste Gulbenkian, 2005, p.88-89, é explicito em reconhecer apenas a posse jurídica com garantias previstas em lei.

34 Cf. GAUS, G. The order of Public Reason. A Theory of Freedom and Morality in a diverse and bounded world. New York: Cambridge University Press, 2011, p.21ss.

35 Cf. GAUS, G. Op. Cit. p. 21 ss.

36 NOZICK, R. Anarquia, Estado e Utopia. São Paulo: Martins Fontes, 2011, p.40.37 NAGEL, T. Otras Mentes. Ensayos críticos (1969-1994). Tradução Sandra Girón. Barcelona: Gedisa, 2000, p. 175-177: "Nozick parte de la premissa indiscutible de que los individuos tienen ciertos derechos inviolables que no pueden ser transgredidos intencionalmente por outros individuos, o por el Estado, para ningún propósito. Se trata de los derechos a no ser matado o atacado si uno no está haciendo ningún daño, a no ser forzado a encarcelado, a que no se robe o destruya la propiedad, a no ser limitado en el uso de la propiedade, siempre que uno no viole los derechos de los demás. Concluye que el único Estado moralmente permisible sería el Estado mínimo guardián, um Estado limitado a proteger a la gente de asesinatos, ataques, robos, fraude y violación de contratos (...). El ejercicio del poder del Estado no es la acción de una entidade separada com más derechos morales que los de los indivíduos, derechos a usar la fuerza contra personas por razones que no justificarian el uso de la fuerza por individuos o grupos de individuos per se. Si los gobiernos tienen el derecho a la coerción, debe ser um derecho de las personas, que establecen y apoyan instituciones gubernamentales, y de quienes actúan en su nombre. Hay un problema en enunciar esta posición de modo tal de evitar banalidad. Para alguien que cree que los gobiernos tienen derechos mucho más amplios que los individuos, siempre se podría agregar que la existência de tales derechos implica el derecho individual correspondiente de combinarse com otros para instaurar um gobierno 
y actuar por médio de él a fin de ejercer derechos más amplios de coerción y control. Pero, según esa posicioón, estos derechos individuales se derivarían de los derechos del Estado, y no al revés."

38 NAGEL, T. Nozick: libertarismo sem fundamentos. In: Otras Mentes. Ensayos críticos (19691994). Tradução Sandra Girón. Barcelona: Gedisa, 2000, p. 177.

39 HABERMAS, J. Direito e Democracia: entre facticidade e validade. Tradução Flávio Beno Siebeneichler. Rio de Janeiro: Tempo Brasileiro, 1997, vol.1, p. 334.

40 HABERMAS, J. Direito e Democracia: entre facticidade e validade. Tradução Flávio Beno Siebeneichler. Rio de Janeiro: Tempo Brasileiro, 1997, vol.1, p. 185.

41 HABERMAS, J. Op. Cit. p. 192.

42 HABERMAS, J. Op. Cit. p. 192.

43 HABERMAS, J. Direito e Democracia: entre facticidade e validade. Tradução Flávio Beno Siebeneichler. Rio de Janeiro: Tempo Brasileiro, 1997, vol.1, p. 236.

44 HABERMAS, J. Op. Cit. p. 240.

45 HABERMAS, J. Op. Cit. p. 242.

46 HABERMAS, J. Op. Cit. p. 245.

47 HABERMAS, J. Op. Cit. p. 275.

48 HABERMAS, J. Op. Cit. p. 279.

49 HABERMAS, J. Direito e Democracia: entre facticidade e validade. Tradução Flávio Beno Siebeneichler. Rio de Janeiro: Tempo Brasileiro, 1997, vol.1, p. 343: nesse sentido o tribunal constitucional deve ser o mediador entre os interesses práticos da política real e os ideais republicanos, Habermas concorda esse argumento do liberal Bruce Ackerman, mas frisa o papel construtivo da democracia deliberativa.

50 HABERMAS, J. Op. Cit. p. 347.

51 HABERMAS, J. Op. Cit. p. 336.

52 HABERMAS, J. Op. Cit. p. 334.

53 HABERMAS, J. Op. Cit. p. 335.

54 HABERMAS, J. Op. Cit. p. 345. Michelman e Perry entendem a Constituição como produto de uma reflexão política ética de uma comunidade, para Habermas (Op. Cit. p. 348) eles não entendem a ideia de interesses gerais da sociedade institucionalizados argumentativamente na democracia e transformando esses potenciais axiológicos comunitários em locus de argumentação, mas Michelman e Perry estão vinculados ao processo de revelação e discussão de valores de uma comunidade ao qual o tribunal constitucional deve ser um garantidor.

55 A defesa dos direitos individuais pelos tribunais é uma clara bandeira liberal como apontam Ackerman e Rawls, Habermas adota uma postura de reconstrução via radicalização democrática da proposta liberal de defesa do cidadão, não apenas protetiva (como a liberdade negativa de não interferência na vida privada, apontada por Berlin na seção 2), mas uma liberdade positiva comunicativa e argumentativa como defendida por Habermas como meio procedimental da democracia deliberativa. Habermas dialoga, na nossa percepção, de uma maneira construtiva com a tradição liberal, embora a recoloque num patamar de deliberação pública como co-construtora das pretensões de poder perante as instituições e não espera apenas uma resposta paternalista do judiciário ou isola o direito constitucional em um ideal utópico sem levar em conta a política real. Ao se afastar de um republicanismo ético de defesa de virtudes comunitaristas e/ou tradicionais, aproximase mais de Kant e sua autonomia pública jurídica e defesa da autonomia privada como meio de proteção do indivíduo e sua capacidade de uso da razão, só que o giro epistemológico da razão em Habermas a recoloca como comunicativa e não monológica. Habermas reforça o ideal kantiano de razão pública enquanto razão comunicativa. Não haverá retorno a uma visão individualista da política como pretende Nozick (seção 2), mas uma política intersubjetivista e construída procedimentalmente sem potenciais éticos orientadores a partir de uma força virtuosa da comunidade (como quis Rousseau ou como querem os atuais comunitaristas éticos). 